\title{
Diurnal and annual variations of meteor rates at the arctic circle
}

\author{
W. Singer, U. von Zahn, and J. Weiß \\ Leibniz-Institute of Atmospheric Physics, 18225 Kühlungsborn, Germany \\ Received: 15 October 2003 - Published in Atmos. Chem. Phys. Discuss.: 6 November 2003 \\ Revised: 28 July 2004 - Accepted: 28 July 2004 - Published: 23 August 2004
}

\begin{abstract}
Meteors are an important source for (a) the metal atoms of the upper atmosphere metal layers and (b) for condensation nuclei, the existence of which are a prerequisite for the formation of noctilucent cloud particles in the polar mesopause region. For a better understanding of these phenomena, it would be helpful to know accurately the annual and diurnal variations of meteor rates. So far, these rates have been little studied at polar latitudes. Therefore we have used the $33 \mathrm{MHz}$ meteor radar of the ALOMAR observatory at $69^{\circ} \mathrm{N}$ to measure the meteor rates at this location for two full annual cycles. This site, being within $3^{\circ}$ of the Arctic circle, offers in addition an interesting capability: The axis of its antenna field points (almost) towards the North ecliptic pole once each day of the year. In this particular viewing direction, the radar monitors the meteoroid influx from (almost) the entire ecliptic Northern hemisphere.

We report on the observed diurnal variations (averaged over one month) of meteor rates and their significant alterations throughout the year. The ratio of maximum over minimum meteor rates throughout one diurnal cycle is in January and February about 5, from April through December $2.3 \pm 0.3$. If compared with similar measurements at midlatitudes, our expectation, that the amplitude of the diurnal variation is to decrease towards the North pole, is not really borne out.
\end{abstract}

Observations with the antenna axis pointing towards the North ecliptic pole showed that the rate of deposition of meteoric dust is substantially larger during the Arctic NLC season than the annual mean deposition rate. The daylight meteor showers of the Arietids, Zeta Perseids, and Beta Taurids supposedly contribute considerably to the June maximum of meteor rates. We note, though, that with the radar antenna pointing as described above, all three meteor radiants are close to the local horizon but all three radiants were detected.

Correspondence to: $\mathrm{W}$. Singer

(singer@iap-kborn.de)

\section{Introduction}

A meteoroid is a small particle travelling in interplanetary space. In the case that it enters the Earth's upper atmosphere its interactions with the air molecules give rise to an extended trail of ionization (detectable by radars) and, if the meteoroid is large and fast enough, to a brief streak of light (the visible meteor). As common in the literature, we will apply the designation 'meteor' in the following also to the radar-detected trail of ionization. The ablation of meteoroids during their high-speed entry into the Earth's atmosphere is an important source for (a) the metal atoms of the upper atmosphere metal layers and (b) also for the formation of nanometer-sized condensation nuclei $(\mathrm{CN})$. The existence of these $\mathrm{CNs}$ is a prerequisite for the subsequent formation of noctilucent cloud particles in the polar mesopause region. For a better understanding of these phenomena, it is helpful to know accurately the annual and diurnal variations of meteor rates. These rates have been extensively studied at mid and low latitude, starting with the imposing work of Hawkins (1956) at Jodrell Bank $\left(53^{\circ} \mathrm{N}\right)$. Among his many results are the conclusions that the space density of meteors along the length of the Earth's orbit clearly peaks in June and that the radiants of the sporadic meteors are concentrated towards the plane of the ecliptic. In comparison, few studies have been published on meteor rates and their temporal variations at polar latitudes. Therefore we have integrated a $33 \mathrm{MHz}$ SKiYMET all-sky meteor radar into the instrument cluster of the ALOMAR observatory at $69^{\circ} \mathrm{N}$ latitude and have measured the radar meteor rates at this location for two full annual cycles. This site, being within $3^{\circ}$ of the Arctic circle, offers in addition an interesting capability: The axis of its antenna field points (almost) towards the North ecliptic pole (=NEP) once each day of the year. In this particular viewing direction, the radar monitors the meteoroid influx from (almost) the entire ecliptic Northern hemisphere. Hence, the radar is excellently suited to measure the spatial variations of that meteoroid influx, which originates in the ecliptic Northern hemisphere, 

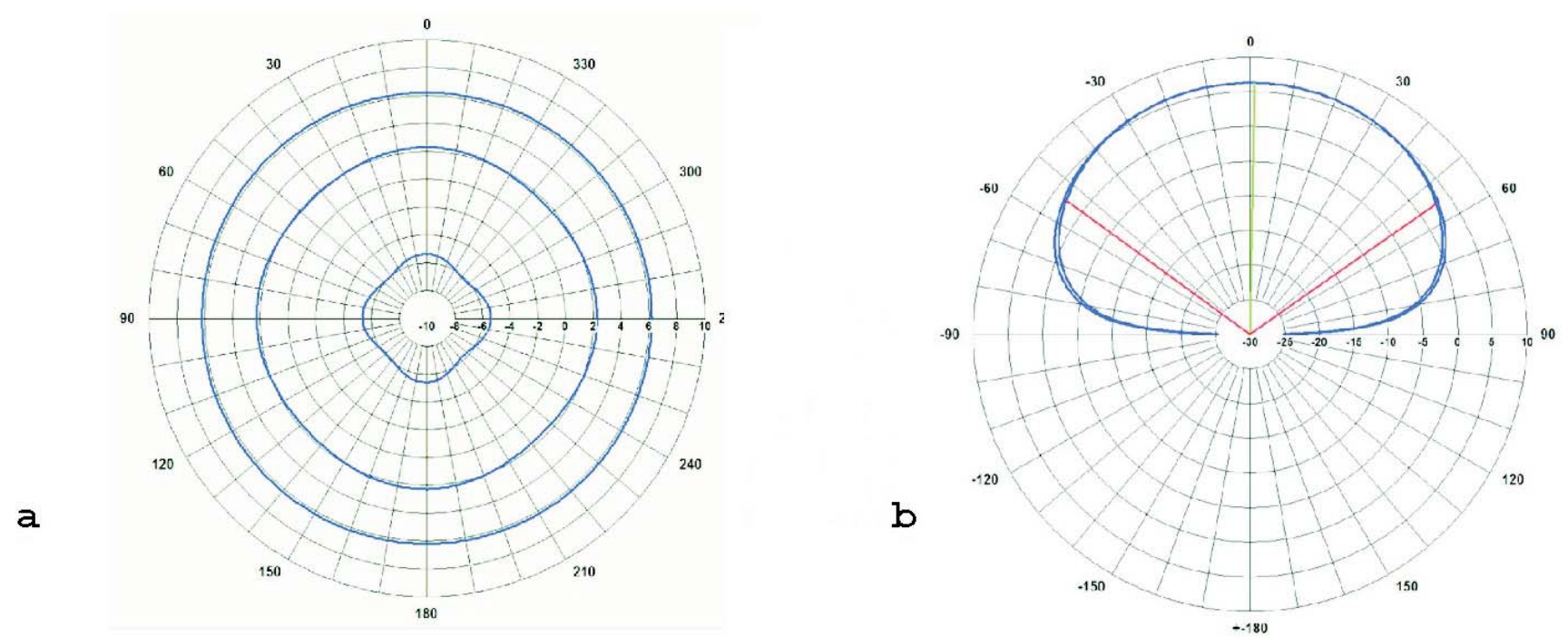

Fig. 1. Two-element crossed receive antenna of the SKiYMET radar. Panel (a): Horizontal radiation pattern with azimuthal cuts at $10^{\circ}, 60^{\circ}$ and $80^{\circ}$ zenith angle; Panel (b): Vertical radiation pattern with zenithal cuts at $0^{\circ}$ and $45^{\circ}$ azimuth and a $3-\mathrm{dB}$ beam width of $109^{\circ}$ (courtesy of Genesis Software).

along the path of the Earth about the Sun. Here we report on the observed diurnal variations (averaged over one month) of meteor rates and their significant alterations throughout the year

\section{The radar instrument: its parameters and sites}

This study was performed using a commercially produced SKiYMET all-sky interferometer meteor radar (Hocking et al., 2001). Its basic instrument parameters are:

$\begin{array}{ll}\text { frequency } & 32.55 \mathrm{MHz} \\ \text { peak power } & 12 \mathrm{~kW} \\ \text { pulse width } & 13 \mu \mathrm{s} \\ \text { pulse rep. frequency } & 2144 \mathrm{~Hz} \\ \text { transmitting antenna } & \text { 3-element crossed Yagi antenna } \\ \text { receiving antenna } & 5 \text {-channel interferometer } \\ & \text { of 2-element crossed Yagi antennas } \\ \text { sampling resolution } & 0.94 \mathrm{~ms} \\ \text { height range } & 78-120 \mathrm{~km} \\ \text { angular resolution } & 2^{\circ}\end{array}$

The radar antennas apply crossed antenna elements to ensure a near uniform azimuthal sensitivity to meteor echoes as shown in Fig. 1a for the receiver antenna. The system uses a 5-antenna interferometer on reception, resulting in a range accuracy of $2 \mathrm{~km}$ and angular accuracy of 1 to $2^{\circ}$ in meteor location. The dependence of the receiver antenna gain on the elevation is shown in Fig. 1b. It is rather uniform for zenith angles less than, say, $60^{\circ}$ and tends towards zero for echoes close to the local horizon. We note that the system detects only meteor trails oriented perpendicular to the radial direc- tion from the radar to the meteor trail. Still, the gain pattern implies a rather well behaved detection efficiency for meteors from all directions except for those entering close to the vertical.

Meteor entry velocities can be estimated from about $5 \%$ of the detections using the phase oscillations prior and after the peak in the signal amplitude and a radiant determination is possible on a statistical basis (for details see Hocking et al., 2001).

A theoretical estimate for the limiting meteor sensitivity of the radar is obtained using the minimum detectable power $P_{\text {noise }}$ at the antenna determined from a sky noise map for $45 \mathrm{MHz}$ at $69^{\circ} \mathrm{N}$ (Campistron et al., 2001) after Eqs. (1) and (2), where $k$ is Boltzman's constant.

$P_{\text {noise }}=\left(T_{A}+T_{r}\right) k B=\left\{T_{A}+T_{0}(F-1)\right\}$
$T_{A}=T_{32.55 \mathrm{MHz}}=T_{45 \mathrm{MHz}}(32.55 / 45)^{-2.5}$

We use the bandwidth of the receiver, $B=50 \mathrm{kHz}$, and correct also for the small additional receiver noise at $T_{0}=290 \mathrm{~K}$ with its noise figure, $F=4$. Using a sky temperature $T_{A}=8000 \mathrm{~K}$ a value of $P_{\text {noise }}=1.3 \cdot 10^{-14} \mathrm{~W}$ results. Only echoes about $10 \mathrm{~dB}$ above the cosmic noise floor will be detected, so the practical detection threshold power is $P_{t h}=1.3 \cdot 10^{-13} \mathrm{~W}$. For a peak power $P_{t}$ of $12 \mathrm{~kW}$ and a cable loss of about $1 \mathrm{~dB}$, a radar frequency $f$, the speed of light $c$, and an antenna directivity ( $D=5.4)$ at a minimum range $R$ of $80 \mathrm{~km}$, the minimum threshold power corresponds according to Eq. (3) to a minimum detectable electron line density of $q_{\text {lim }}=3.6 \cdot 10^{12}$ electrons $/ \mathrm{m}$ (McKinley, 1961).

$q_{\text {lim }}=\left\{\left(P_{t h} R^{3}\right) /\left(2.5 \cdot 10^{-32} P_{t} D^{2}(c / f)^{3}\right)\right\}^{1 / 2}$

$M=40-2.5 \log q_{\text {lim }}$ 


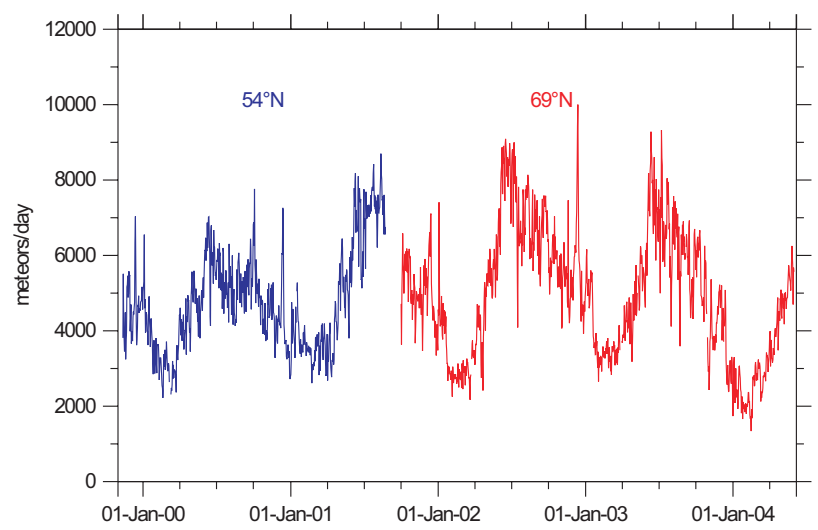

Fig. 2. Annual variation of daily mean meteor count rates at Juliusruh $\left(54^{\circ} \mathrm{N}\right)$ and Andenes $\left(69^{\circ} \mathrm{N}\right)$ between November 1999 and April 2004.

This $q_{\text {lim }}$ corresponds to a meteor of radio magnitude +8.6 using the relation between magnitude and electron line density given by Eq. (4).

From November 1999 until August 2001, the radar was operated at our field station Juliusruh, Germany, with geographic coordinates $54.6^{\circ} \mathrm{N}, 13.4^{\circ} \mathrm{E}$. Thereafter the radar was moved to the ALOMAR observatory, Norway, with geographic coordinates $69.3^{\circ} \mathrm{N}, 16.0^{\circ} \mathrm{E}$ (von Zahn, 1997). There the radar is located $2.6^{\circ} \mathrm{N}$ of the Arctic circle and is in continuous operation since the end of September 2001 (Singer et al., 2003).

The daily meteor count rates are characterized by a strong annual variation (Fig. 2). The largest values are observed in summer (June) and the lowest count rates are detected in winter (February), both, at mid-latitudes as well as at Arctic latitudes. The Leonid shower of November 2002 is also clearly noticeable. Typical distributions of the meteor occurrence in dependence on height and on decay time are depicted in Fig. 3. The distributions are normalized to their peak values. The meteor layer peaks at about $90 \mathrm{~km}$ in winter with a half width of about $19 \mathrm{~km}$. In summer, the peak altitude is approximately $92 \mathrm{~km}$ and the layer is narrower with a half width of about $12 \mathrm{~km}$.

For any site on the Arctic circle, the NEP passes through the zenith once a day. We show in Fig. 4 an idealized sketch of this viewing geometry. In this figure, the actual elevation pattern of Fig. $1 \mathrm{~b}$ is idealized to a mushroom shape. We remind the reader, though, that the actual elevation pattern cuts out from detections those meteors which enter nearly vertically. Otherwise, meteoroids can be observed which enter in (almost) all directions from the ecliptic Northern hemisphere, none can be observed entering from the South ecliptic hemisphere. Such geometry seems well suited to study the variation of meteoroid fluxes along the path of the Earth about the Sun. For this geometry to occur, the local time needs to be 06:00 LT, 24:00 LT, 18:00 LT, and 12:00 LT close to the spring equinox, the summer solstices, the autumn

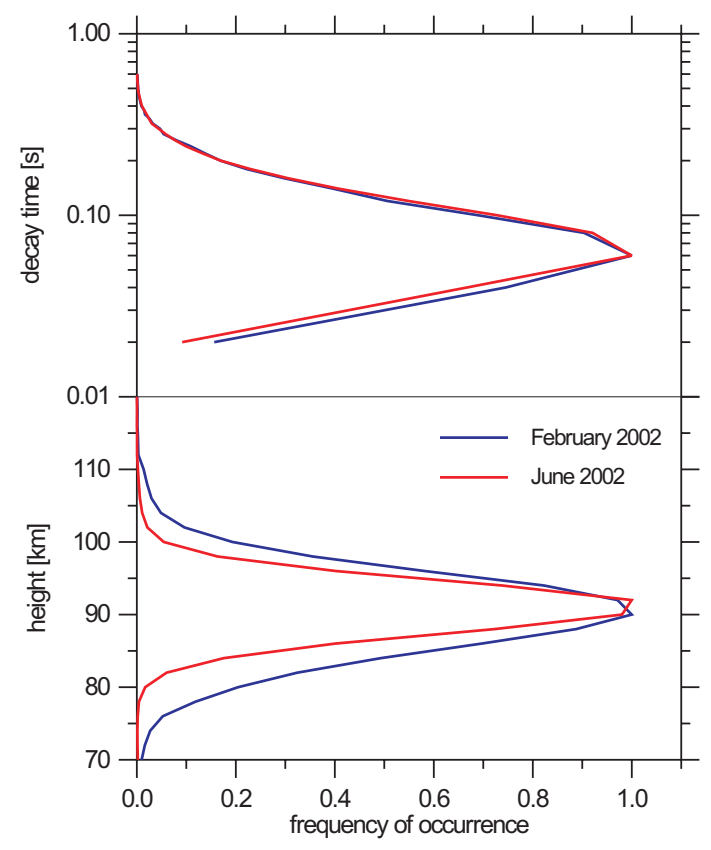

Fig. 3. Monthly mean distributions of the meteor occurrence at Andenes. The peak rates are 9271 meteors in February 2002 and 47753 meteors in June 2002.

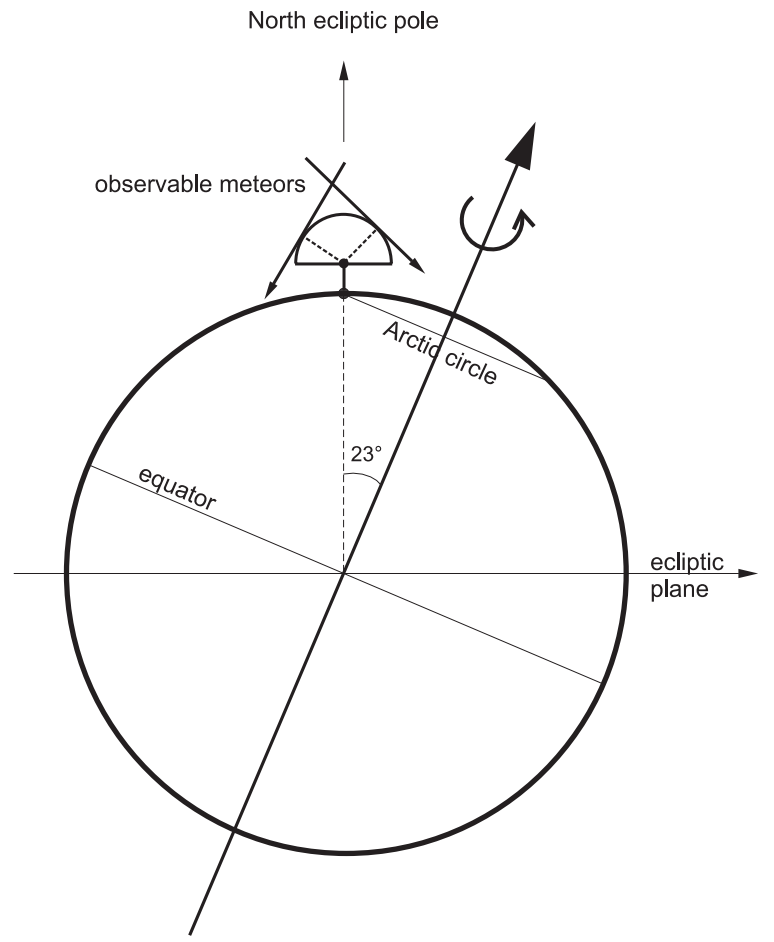

Fig. 4. Schematic of the viewing geometry of a SKiYMET radar located on the Arctic circle. The mushroom-like feature at the radar site is to mimic the idealized elevation pattern of the instrument sensitivity. Meteor trails have to be at a right angle to this feature in order to be detectable by the radar. 


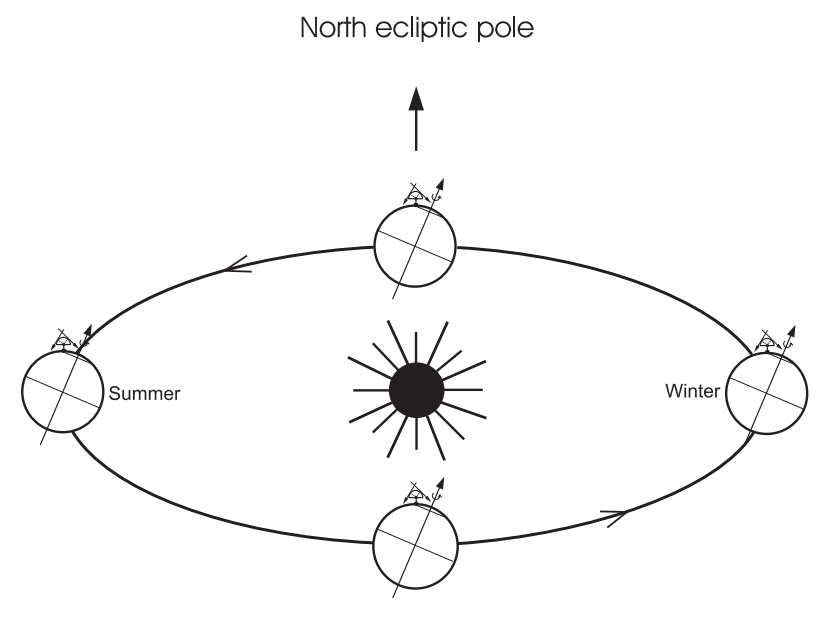

Fig. 5. Illustration of the radar capability to look towards the North ecliptic pole once each day of the year.

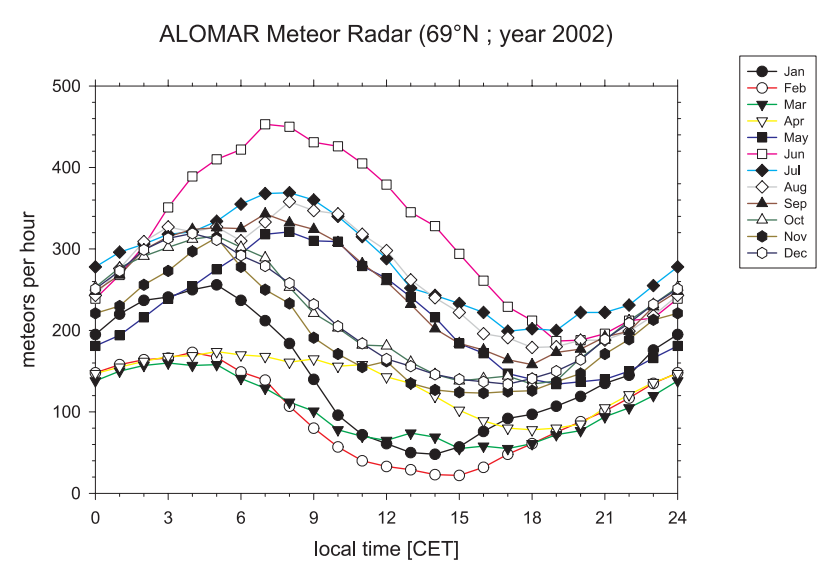

Fig. 6. Monthly means of the diurnal variations in meteor rates throughout the year 2002 .

equinox and the winter solstices, respectively (Fig. 5). We recognize that the ALOMAR site is located $2.6^{\circ} \mathrm{N}$ of the Arctic circle. This offset is, however, only of the same size or smaller than the diameter of most meteor streams and therefore we consider it unimportant for our following considerations.

\section{Diurnal variations of meteor rates}

We show in Fig. 6 monthly means of the meteor rates as observed at the ALOMAR site and as function of Central European Time (CET). The latter is only a few minutes different from the local solar time at the radar site. Total meteor count rates covering the height range 75 to $120 \mathrm{~km}$ were calculated from the raw data after removal of multiple detections and counting ambiguous detections in range only once. Only unambiguous detections were allowed for meteors with altitude above $100 \mathrm{~km}$. Furthermore, there was no attempt made to eliminate shower meteors from these statistics. Un-
Table 1. The ratio of maximum over minimum meteor rates throughout one diurnal cycle for the year 2002 (The *February value is a mean of 2002 and 2003).

\begin{tabular}{cccccc}
\hline Jan. & Feb.* $^{*}$ & March & April & May & June \\
\hline 5.6 & 5.1 & 2.8 & 2.3 & 2.5 & 2.5 \\
\hline & & & & & \\
\hline July & Aug. & Sept. & Oct. & Nov. & Dec. \\
\hline 2.0 & 2.0 & 2.2 & 2.4 & 2.6 & 2.4 \\
\hline
\end{tabular}

der these rules, the instrument yields meteor rates in the order of $250 \pm 200$ meteors per hour.

Absolute maximum and minimum meteor rates are reached near 07:00 LT in June and 15:00 LT in February, respectively, their ratio being about 20 (a day-by-day analysis of February data shows that the absolute minimum of meteor rates is reached during the first week of February). The fact that the meteor count rate maximizes in June is of great significance for the aeronomy of noctilucent clouds. It very likely means that also the total meteoric mass flux maximizes during June. The latter is assumed to be the dominant source for condensation nuclei $(\mathrm{CN})$ in the altitude range 75 to $90 \mathrm{~km}$. The existence of these CNs is a prerequisite for the formation of noctilucent cloud particles in the polar mesopause region (von Zahn and Berger, 2003).

The ratio of maximum over minimum meteor rates throughout one diurnal cycle is given in Table 1 for each month of the year 2002. In January and February this ratio is about 5, from April through December 2.3 \pm 0.3 . If compared with similar measurements at mid-latitudes (e.g. Nakamura et al., 1991), our expectation, that the amplitude of the diurnal variation is to decrease towards the North pole, is not really borne out.

In order to evaluate the reproducibility of the diurnal variations, we show in Fig. 7 monthly mean variations of meteor rates for June and February for both the years 2002 and 2003. According to Fig. 6, these are at our observation site the months with maximum and minimum total meteor rates, respectively. Very conspicuous are not only the large differences in meteor rates between the two months, but also the variability of the local times at which the maximum and minimum rates occur. If the diurnal variation would be driven solely by the orbital motion of the Earth about the Sun, the maxima and minima should occur at 06:00 and 18:00 LT, respectively. Actual deviations from this first-approximation values reach up to $5 \mathrm{~h}$ or $75^{\circ}$ of a full diurnal cycle. Clearly, higher order effects than just the orbital motion of the Earth contribute significantly to the shape of the diurnal variation curve. 


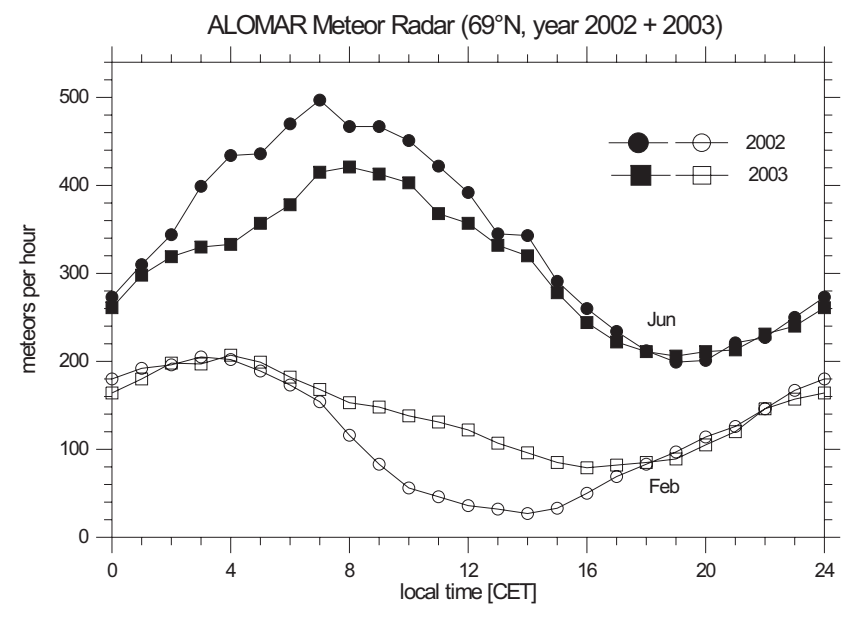

Fig. 7. Monthly means of the diurnal variation in meteor rates for February and June of the years 2002 and 2003.

\section{Annual variation of observed meteors}

\subsection{Annual variation of diurnally averaged meteor rates}

Monthly means of the diurnal variations in meteor rates as observed by our ALOMAR meteor radar have been shown already in Fig. 6 and indicate a clear maximum of this rate during the month of June, the minimum in February. This general character of the observed annual variation can be recognized also in Fig. 2, the presentation of our raw data.

We compare in Fig. 8 the annual variation of meteor rates as observed at different Northern latitudes by our meteor radars at $69^{\circ} \mathrm{N}$ (ALOMAR) and $54^{\circ} \mathrm{N}$ (Juliusruh), respectively. The relative change from maximum to minimum rate has become somewhat smaller in going to a lower latitude, but no major difference is discernible. A strong June/July maximum and February minimum of meteor rates was found much earlier also by Hawkins (1956) with his radar located at $53^{\circ} \mathrm{N}$ (Jodrell Bank) who summarizes his result as follows: "There is a dense complex of orbits in the region traversed by the Earth during the months May to August". We note, though, that there exists a small difference in the local time at which the June maxima occur. For our $54^{\circ} \mathrm{N}$ radar this near 06:00 LT, for Hawkins' $53^{\circ} \mathrm{N}$ radar it is more in the late morning hours. Any significance of this small difference remains to be studied.

4.2 Annual variation of observed meteors arriving from the ecliptic Northern hemisphere

As explained in Sect. 2, at our observation site the NEP passes close to the zenith once a day. The local times that this happens are e.g. 02:25, 00:23, and 22:25 LT for 15 May, 15 June, and 15 July, respectively. We can follow this coincidence throughout the year and Fig. 9 shows the number of meteors observed over a period of one hour, each centered

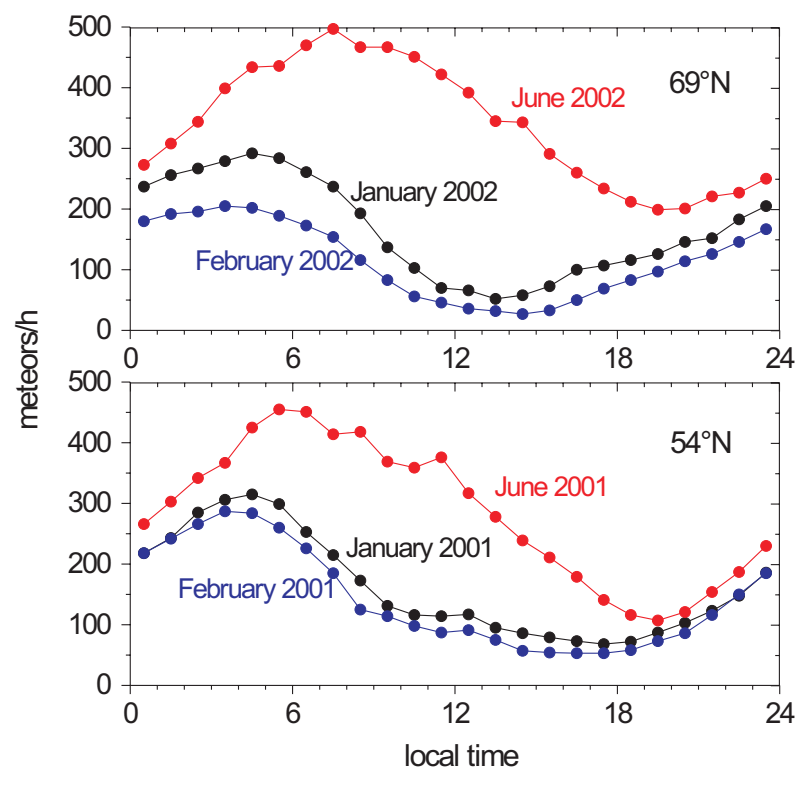

Fig. 8. Monthly means of the diurnal variation in meteor rates for January, February, and June at mid-latitudes and Arctic latitudes.

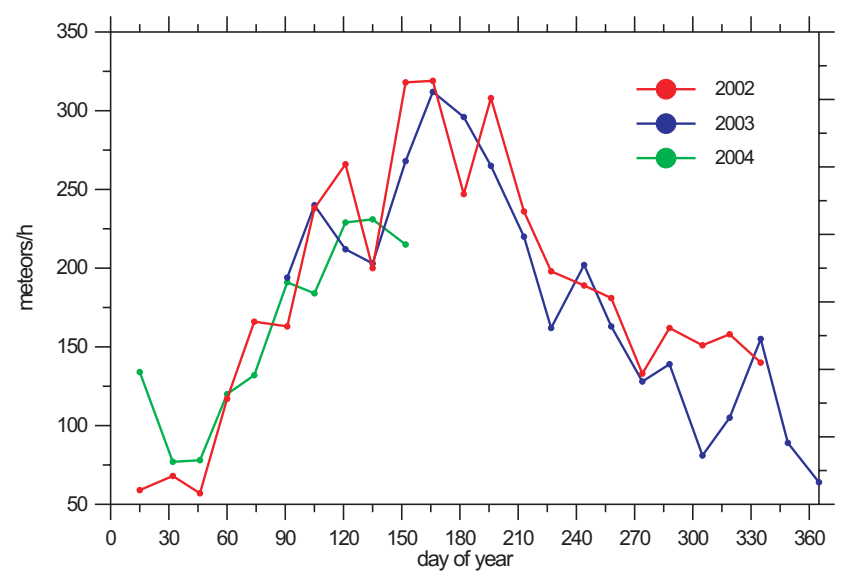

Fig. 9. Annual variation of the meteor rate with the NEP close to the zenith at the radar site. Plotted are the number of meteors for a $1 \mathrm{~h}$ period, centered on the local time of closest approach of the NEP to the zenith in the years 2002, 2003, and 2004.

on the local time of passage of the NEP close to the zenith. Even under this special viewing geometry, a strong annual variation of meteor rate is clearly present and with the maximum rate occurring in June. This is one more proof that the total meteoric flux entering the Earth's atmosphere from the North ecliptic hemisphere depends strongly on the position of the Earth along its orbit about the Sun, that is on ecliptic longitude.

To analyse the situation further, we will now study the altitude distribution of the observed meteors. Figure 10 show the altitude distribution of all detected meteors during the one hour of "NEP-close-to-zenith" for the days of maximum 


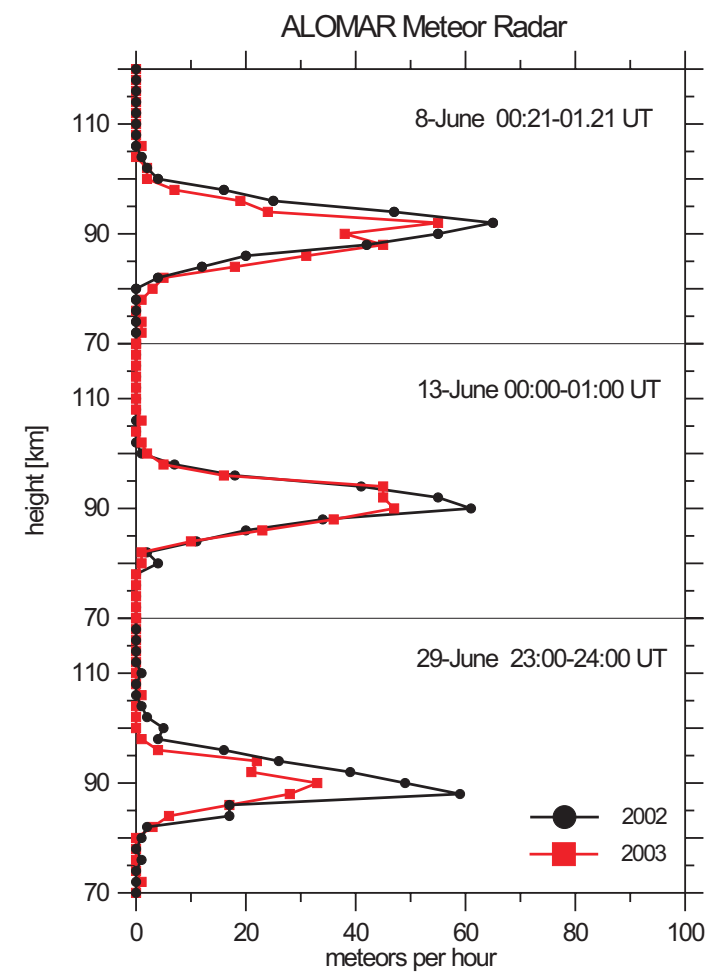

Fig. 10. The altitude distribution of all detected meteors during the one hour of "NEP-close-to-zenith" for the dates of maximum activity of the three June daylight showers (8 June - Arietids, 13 June - Zeta Perseids, 29 June - Beta Taurids). The meteor rates are shown separately for the years 2002 and 2003.

activity of the three June daylight showers. Black lines indicate the observations of 2002, the red ones those of 2003. The distribution peaks at $92 \mathrm{~km}$ in early June and at $88 \mathrm{~km}$ in late June. This may indicate a lessening influence of the fast, early-June Arietids on the gross distributions. The occurrence peak of the Arietids was found by Browne et al. (1956) also near $92 \mathrm{~km}$ in their Jodrell Bank observations. Their occurrence distribution extends, however, to $110 \mathrm{~km}$ altitude at undoubtedly higher radiant altitudes than studied by us. The difference of meteor rates observed by the two radars at altitudes above $95 \mathrm{~km}$ could well be caused by a rapid decrease of detection efficiency of our SKiYMET radar for meteor trails at and above this altitude. We note, though, that trails of Leonid meteoroids have been clearly detected even above $110 \mathrm{~km}$ by our SKiYMET radar (Singer et al., 2000) which is probably helped greatly by the high entry velocity (and thus ionization efficiency) of these meteoroids. Hence, the loss of detection efficiency of our radar above $100 \mathrm{~km}$ is not necessarily a sharp cut-off.

The question has been raised whether all or part of the strong annual variation in meteor rates as shown here in Figs. 2 and 9 could be caused by annual variations of the atmospheric density or density scale height at meteor altitudes? This topic has been theoretically studied by e.g. Ellyett and Kennewall (1980) who conclude that such a sug-

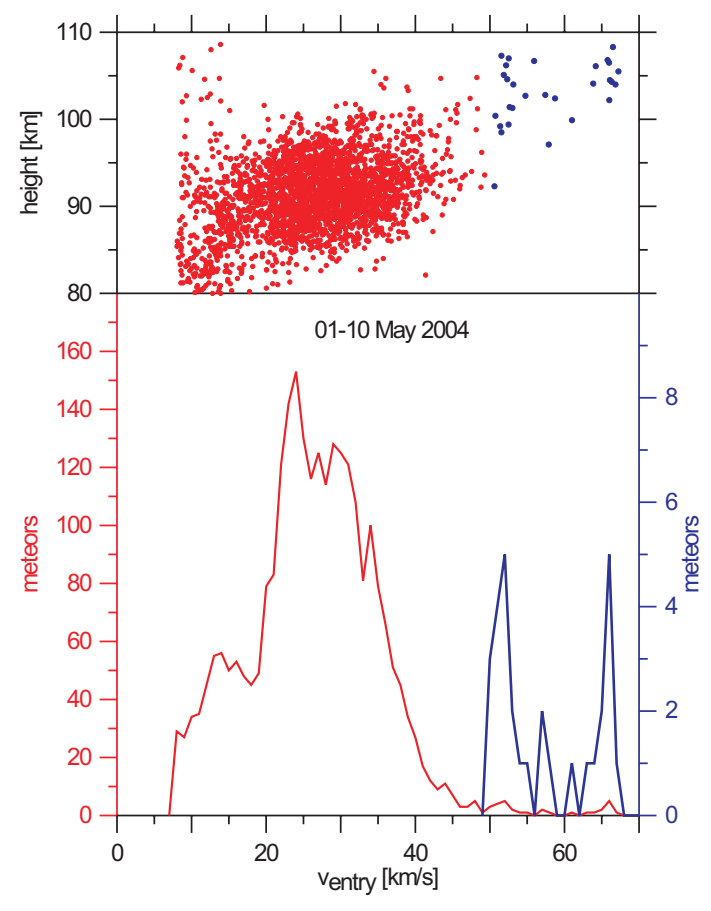

Fig. 11. The height distribution of entry velocities and their occurrence observed at ALOMAR during the Eta Aquarid shower in May 2004. The blue line represents meteors with entry velocities greater than $50 \mathrm{~km} / \mathrm{s}$ at an enhanced scale.

gestion is at least plausible. The location of our radar is unique in the sense that it observes a mesopause region which might well be called the best-investigated of all. This mesopause region above the Andya Rocket Range and ALO$\operatorname{MAR}\left(69^{\circ} \mathrm{N}, 16^{\circ} \mathrm{E}\right)$ has been studied for decades using instruments aboard sounding rockets and meteorological rockets as well as ground-based lidars, radars, and night glow spectrometers. We thus try to summarize some relevant results of this work.

The meteor rates, observed by the ALOMAR meteor radar, maximize close to $90 \mathrm{~km}$ altitude (Fig. 10). It so happens that at this altitude, a minimal seasonal change of number density occurs. The ratio of number densities in (January-March) over those in (July+August), as obtained from rocket-borne ionization gages is $0.5,1.0$, and 1.8 at 80,90 , and $100 \mathrm{~km}$ altitude, respectively (Rapp et al., 2001). More generally speaking, if one takes the mean June density as reference, the densities from spring through autumn stay within the range of $\pm 10 \%$. In fact, the variations are so small that the error bars allow a density in spring which can be either smaller or larger than in June. According to our Fig. 9, the meteor rate varies, however, by a factor of almost 2 from late March/early April to June. This increase can clearly not be attributed to the seasonal density change at $90 \mathrm{~km}$ altitude.

Can a change in density scale height $H_{n}$ explain part or all the change in meteor rate? In the altitude range 90 to $100 \mathrm{~km}, H_{n}$ is smallest in the period July+August, but it 
Table 2. Summer daylight showers (from literature).

\begin{tabular}{|c|c|c|c|c|}
\hline Shower & Eta Aquarids & Arietids & Zeta Perseids & Beta Taurids \\
\hline Date of peak & 4/5 May & 8 June & 13 June & 29 June \\
\hline Radiant RA [h, min] & $22 \mathrm{~h} 30 \mathrm{~min}$ & $03 \mathrm{~h} 00 \mathrm{~min}$ & $04 \mathrm{~h} 12 \mathrm{~min}$ & $05 \mathrm{~h} 16 \mathrm{~min}$ \\
\hline Radiant RA $\left[^{\circ}\right]$ & 337.5 & 45 & 63 & 79 \\
\hline Radiant Dec $\left[{ }^{\circ}\right]$ & -1.3 & +24 & +26 & +21 \\
\hline $\mathrm{LT}$ of radiant transit & 09:10 & $10: 50$ & $11: 45$ & $11: 40$ \\
\hline Radiant altitude for NEP in zenith $\left[{ }^{\circ}\right]$ & +8 & +7 & +7 & +1 \\
\hline Time when NEP and zenith are closest together & 03:04 LT & 00:51 LT & 00:30 LT & 23:28 LT \\
\hline Entry velocity $[\mathrm{km} / \mathrm{s}]$ & 64 & 39 & 29 & 31 \\
\hline Equivalent visual ZHR & $20-60$ & 60 & 40 & 20 \\
\hline Period $[y]$ & 8 & 2.0 & 2.0 & 3.3 \\
\hline Perihel distance [AU] & 0.57 & 0.09 & 0.35 & 0.34 \\
\hline Eccentricity & 0.95 & 0.94 & 0.79 & 0.85 \\
\hline Ecliptic inclination & 164 & 21 & 0 & 6 \\
\hline
\end{tabular}

is only a factor 1.34 larger in January-March period (Rapp et al., 2001). It seems unlikely that this factor can produce the observed factor-2-change in meteor rate. Furthermore, if large density scale heights lead automatically to small meteor rates as argued by Ellyett and Kennewall (1980), then the rate should be smaller in September/October than JanuaryMarch. This is not observed.

As the density scale height is a function of ambient temperature, we should check the available temperature information too: (a) In the Lübken (1999) temperature climatology, the $90 \mathrm{~km}$ temperature stays in the very narrow temperature range of $135 \pm 2 \mathrm{~K}$ from early June until 1 August, or in other words, it "bottoms out" for no less than 7 weeks. The same feature is found by Müllemann (2003), only $1 \mathrm{~K}$ higher. (b) In the Singer et al. (2004) climatology a similar, though not identical "bottom" of the $90 \mathrm{~km}$ temperature is notable. It extends from about day-of-year (d.o.y.) 170 (19 June) to d.o.y. 220 (8 August). (c) In the Singer et al. (2004) climatology, a rapid rise of the $90 \mathrm{~km}$-temperature happens from d.o.y. 220 (8 August) until d.o.y. 270 (27 September). In this relatively short period, the $90 \mathrm{~km}$-temperature rises from about $135 \mathrm{~K}$ to $195 \mathrm{~K}$. This scenario represents the disappearance of the low-level mesopause at the end of the polar summer. The earlier published data of (Singer et al., 2003) show the same two basic features of the $90 \mathrm{~km}$-temperature with the temperature increase at the end of the polar summer concentrated into an even shorter transition period (late August until the end of September).

If one compares these features of the temperature variations with those of the meteor rate (as shown in our Fig. 9), we conclude: The "bottoming-out" temperature feature in June/July can hardly be discerned in the meteor rate variation. The maximum meteor rate about mid-June is sustained for only one month and is neighbored by lesser values on either side (May and July). Furthermore, the rapid September increase in $90 \mathrm{~km}$-temperature (and hence scale height) is not reflected in the observed meteor rates as shown in Fig. 6 for which the steepest decrease of meteor rate occurs about one month before the period of rapid temperature increase.

In summary, the observed properties of the mesopause above ALOMAR do not support a notion that a major part of the observed annual variation in meteor rate is caused by annual variations in the ambient atmosphere.

\subsection{Summer daytime showers}

Meteor radars have long identified a number of prominent meteor showers in summer. The strongest of the May/June period are listed with some of their properties in Table 2 (radiants from Kronk (2003); other parameters from McKinley (1961)). It is remarkable that all four are "daylight" showers in the sense that their radiant transits occur some times between 09:00 and 12:00 LT. The Eta Aquarid shower in early May shows up clearly in our radar data despite low count rates, only 28 meteors with entry velocities above $50 \mathrm{~km} / \mathrm{s}$ have been observed within 10 days (blue line and dots in Fig. 11). This enhanced visibility is most likely due to the high entry speed $v_{a t} \approx 64 \mathrm{~km} / \mathrm{s}$ of these shower meteoroids which cause their electron line density q to be enhanced over that of slower meteors by about $v_{a t}^{3.4}$ (Bronshten, 1983). From both peaks of the velocity distribution for entry velocities greater than $50 \mathrm{~km} / \mathrm{s}$ similar radiants could be determined (50-54 km/s: RA $22 \mathrm{~h} 37 \mathrm{~min}$, Dec $-1^{\circ}$; $64-68 \mathrm{~km} / \mathrm{s}$ : RA $22 \mathrm{~h} 41 \mathrm{~min}$; Dec $-1^{\circ}$ ). The agreement of the two independent results is quite satisfying.

In a mass plot of the hourly meteor counts at Andenes in June 2002 (Fig. 12) three peaks are clearly recognizable between 06:00 and 10:00 UT which are related to the Arietids, Zeta Perseids, and Beta Taurids as shown below. In 2002 our observed meteor rate peaks between 7-8 June (Arietids), between 11-18 June (Zeta Perseids), and between 2529 June (Beta Taurids). The contribution of the three daytime 
Table 3. Summer daylight showers (from observations at $69^{\circ} \mathrm{N}$ ).

\begin{tabular}{lccc}
\hline Shower & Arietids & Zeta Perseids & Beta Taurids \\
\hline Date of radiant estimate 2002 & $7-8$ June & $11-18$ June & 26-28 June \\
Shower velocity range $[\mathrm{km} / \mathrm{s}]$ & $36-44$ & $28-30$ & $30-34$ \\
Radiant RA $[\mathrm{h}, \mathrm{min}]$ & $03 \mathrm{~h} 10 \mathrm{~min} \pm 20 \mathrm{~min}$ & $04 \mathrm{~h} 14 \mathrm{~min} \pm 20 \mathrm{~min}$ & $06 \mathrm{~h} 02 \mathrm{~min} \pm 20 \mathrm{~min}$ \\
Radiant Dec $\left[{ }^{\circ}\right]$ & $+27 \pm 3$ & $+31 \pm 3$ & $+23 \pm 3$ \\
Meteors, with shower velocity $N_{\text {shower }}$ & 72 & 127 & 71 \\
Meteors, all velocities $N_{\text {all }}$ & 947 & 3907 & 1332 \\
Ratio $N_{\text {shower }} / N_{\text {all }}[\%]$ & 8 & 3 & 5 \\
\hline
\end{tabular}

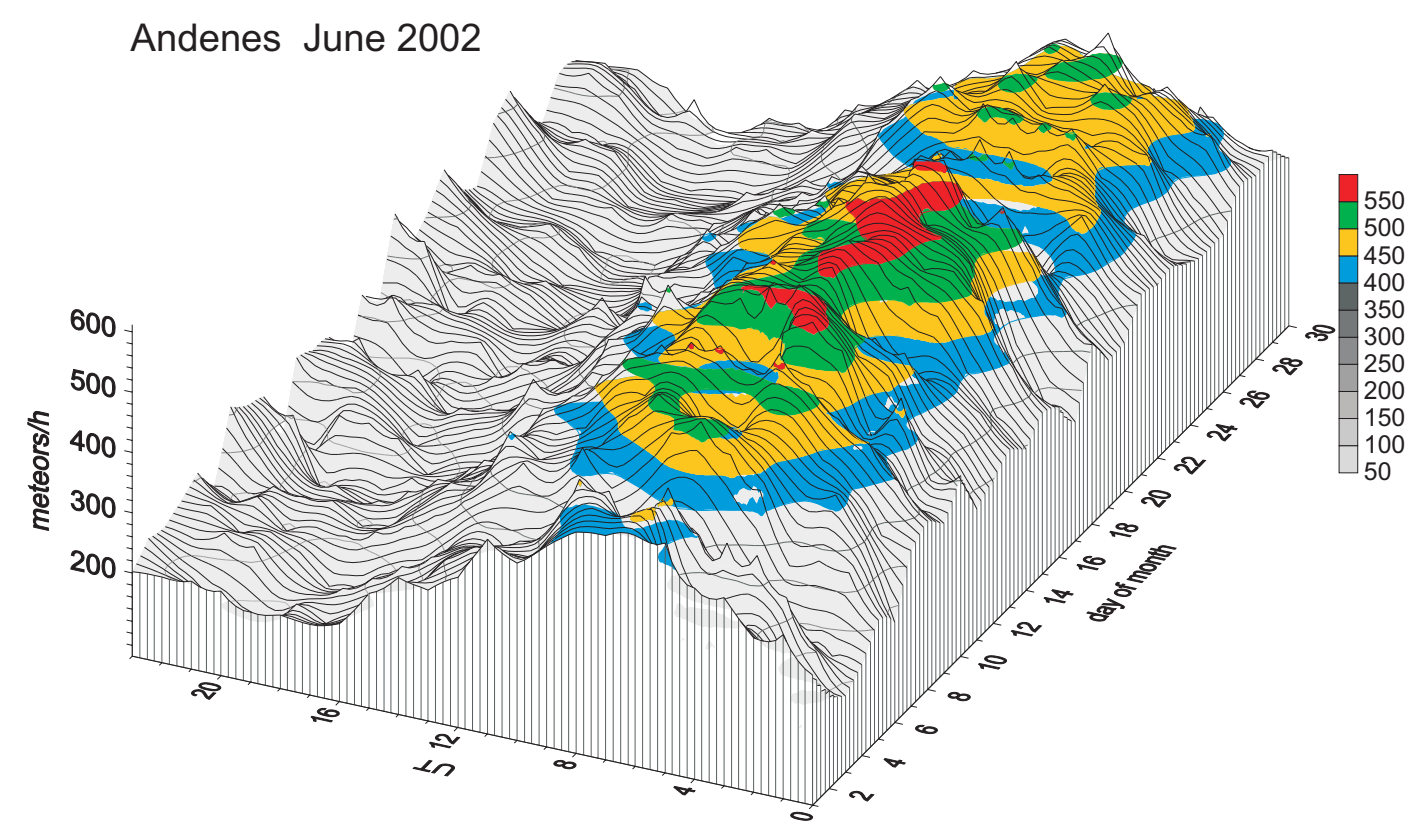

Fig. 12. The diurnal variation of hourly meteor counts observed at Andenes in June 2002.

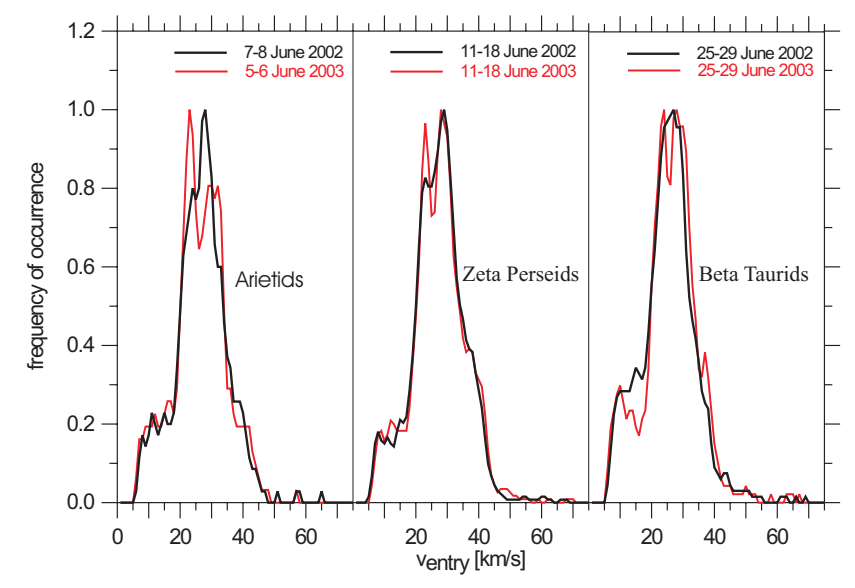

Fig. 13. Normalized occurrence of entry velocities during the daytime meteor showers at Andenes in June 2002 and 2003. showers to the total meteor rate has been estimated in the following way.

For each of the shower periods meteors are selected for a narrow range of entry velocities centred to the corresponding shower velocity (see Table 3 and Fig. 13) and from these meteors a radiant is determined. We found in all cases well defined radiants (Table 3) which are in good agreement with the radiants given in Table 2 . The ratio of meteors in the selected shower velocity band to all meteors for which entry velocities were obtained is generally less than $10 \%$.

A general weakness of signatures from these three June showers for our observation conditions can be expected from the low altitude of their radiants. For our "NEP-close-tozenith" condition, the radiants of the Arietids, Zeta Perseids, and Beta Taurids are only $8^{\circ}, 7^{\circ}$, and $7^{\circ}$, respectively, above the local horizon. This should put their meteor trails at rather higher altitudes at which the detection sensitivity of the radar is already strongly reduced. Therefore, we are not really surprised to see so little trace of these showers in our data. 
Yet, it means that the strong June maximum in meteor rates persists even without a significant contribution of these daylight showers. This finding is somewhat different from that of Ueda and Maegawa (2001). They attribute much of their June maximum in meteor rate, derived from forward-scatter radio observations at $36^{\circ} \mathrm{N}$, to the activity of the daylight showers.

\section{Conclusions}

The diurnal variation of meteor rates as observed at a site close to the Arctic circle, is still quite appreciable. The ratio of maximum over minimum meteor rates throughout one diurnal cycle is $2.3 \pm 0.3$ from April through December and is even higher in the remaining months.

The annual variation of meteor rates is described as follows: A strong peak of meteor rate is found for the month of June. This is true while considering all detected meteors (i.e. all LT and all altitudes) and also for those detected under our special "NEP-close-to-zenith" condition. In June and under "NEP-close-to-zenith" conditions, almost all of the meteors are detected at altitudes below $100 \mathrm{~km}$ with their rate maximizing close to $90 \mathrm{~km}$ altitude. A large number of the echoes occur at elevation angles at and below $35^{\circ}$. These altitude and elevation distributions seem to suggest that the meteors observed by our radar in June come from sporadic meteoroids arriving from the North ecliptic hemisphere with reasonably large ecliptic inclinations and low to moderate atmospheric entry velocities. The contribution of the daytime showers is probably not larger than 5 to $8 \%$.

Acknowledgements. This work has been supported in part by grant BR 2023/1-1 of the Deutsche Forschungsgemeinschaft, Bonn, Germany, and the radar operations at Andenes by grant HPRI-CT-1999-00002 of the European Union. The SKiYMET radar system was designed and manufactured by Genesis Software, Adelaide, Australia, and Mardoc Inc., London, Ontario, Canada.

Edited by: D. Janches

\section{References}

Bronshten, V. A.: Physics of Meteor Phenomena, D. Reidel Publ. Co., Dordrecht, Holland, 356, 1983.

Browne, I. C., Bullough, K., Evans, S., and Kaiser, T. R.: Characteristics of radio echoes from meteor trails, II: The distribution of meteor magnitudes and masses, Proc. Phys. Soc., B69, 83-97, 1956.
Campistron, B., Despaux, G., Lothon, M., Klaus, V., Pointin, Y., and Mauprivez, M.: A $45 \mathrm{MHz}$ sky temperature map obtained from the observations of five ST radars, Ann. Geophys., 19, 863 871,2001

Ellyett, C. D. and Kennewell, J. A.: Radar meteor rates and atmospheric density changes, Nature, 287, 521-522, 1980.

Hawkins, G. S.: A radio echo survey of sporadic meteor radiants, Mon. Not. Roy. Astron. Soc., 116, 92-104, 1956.

Hocking, W. K., Fuller, B., and Vandepeer, B.: Real-time determination of meteor-related parameters utilizing modern digital technology, J. Atmos. Solar. Terr. Phys., 63, 155-169, 2001.

Kronk, G. W.: Comets and Meteor Showers, http://comets. amsmeteors.org/, 2003.

Lübken, F.-J.: Thermal structure of the Arctic summer mesosphere, J. Geophys. Res., 104, 9135-9149, 1999.

McKinley, D. W. R.: Meteor Science and Engineering, McGrawHill, New York, 309, 1961.

Müllemann, A.: Temperaturen, Winde und Turbulenz in der polaren Sommer-mesosphre, Ph.D. thesis, 158, Rostock University, Rostock, Germany, 2003.

Nakamura, T., Tsuda, T., Tsutsumi, M., Kita, K., Uehara, T., Kato, S., and Fukao, S.: Meteor wind observations with the MU radar, Radio Sci., 26, 857-869, 1991.

Rapp, M., Gumbel, J., and Lübken, F.-J.: Absolute density measurements in the middle atmosphere, Ann. Geophys., 19, 571-580, 2001.

Singer, W., Hoffmann, P., Mitchell, N. J., and Jacobi, C.: Mesospheric and lower thermospheric winds at middle Europe and Northern Scandinavia during the Leonid 1999 meteor storm, Earth, Moon and Planets, 82-83, 565-574, 2000.

Singer, W., Bremer, J., Hocking, W. K., Weiß, J., Latteck, R., and Zecha, M.: Temperature and wind tides around the summer mesopause at middle and arctic latitudes, Adv. Space Res., 31, 9, 2055-2060, doi:10.1016/S0273-1177(03)00228-X, 2003.

Singer, W., Bremer, J., Weiß, J., Hocking, W. K., Höffner, J., Donner, M., and Espy, P.: Meteor radar observations at middle and Arctic latitudes Part 1. Mean temperatures, J. Atmos. Sol.-Terr. Phys., 66, 607-616, 2004.

Ueda, M. and Maegawa, K.: Results of forward-scatter radio echo observations in 2000, in Proceedings of the Meteoroids 2001 Conference, edited by Warmbein, B., ESA SP-495, 413-418, 2001.

von Zahn, U.: Achievements of ALOMAR, in Proc. 13th ESA Symp. on European Rocket and Balloon Programmes and Related Research, edited by Kaldeich-Schürmann, B., ESA SP-397, 141-159, 1997.

von Zahn, U. and Berger, U.: Persistent ice cloud in the midsummer upper mesosphere at high latitudes: Three-dimensional modeling and cloud interactions with the ambient water vapor, J. Geophys. Res., 108, D8, 8451, doi:10.1029/2002JD002409, 2003. 